\title{
O PASSAdO PRÉ-ISLÂMICO EM AL-ANDALUS: A RECEPÇÃO DA ANTIGUIDADE E A LEGITIMAÇÃO DO PODER OMÍADA NOS SÉCULOS VIII-X1
}

Jorge Elices Ocón

\begin{abstract}
Resumo
Tradicionalmente se considerou que as sociedades islâmicas não tiveram nenhum tipo de interesse por conhecer ou preservar a Antiguidade. Minha contribuição assinala a necessidade de reconsiderar este paradigma. Para isso, analiso um caso particular, que foi o tema de minha tese de doutorado: a recepção da Antiguidade sob o domínio muçulmano na Península Ibérica ou al-Andalus, durante os primeiros séculos (VIII-X d.C.). Este artigo assinala que al-Andalus constitui um cenário único para os estudos de recepção. Revela a existência de uma profunda e inovadora reflexão sobre o passado, que abarca vários aspectos. Por um lado, uma interpretação impressionante das estátuas clássicas, que deixam de serem consideradas ídolos pagãos para serem vistas como talismãs e protetoras de uma cidade ou comunidade. Por outro lado, a apropriação e reelaboração do passado pelos cronistas árabes, com fins políticos e de legitimação.
\end{abstract}

\section{Palabras-chave}

Al-Andalus; recepção; reutilização; estátuas; califado de Córdoba; legitimação.

\section{Resumen}

Tradicionalmente se ha considerado que las sociedades islámicas medievales no tuvieron ningún tipo de interés por conocer o preservar la antigüedad. Mi contribución señala la necesidad de reconsiderar este paradigma. Para ello analizo un caso particular, que fue el tema de mi tesis doctoral: la recepción de la antigüedad bajo dominio musulmán en la Península Ibérica o al-Andalus, durante los primeros siglos (VIII-X d. C).

\footnotetext{
${ }^{1}$ O presente artigo foi redigido a partir de um seminário com o mesmo título, ministrado no CSIC em 14 de dezembro de 2017.

2 Pós-Doutorando - Universidade Federal de São Paulo, São Paulo, Brasil. E-mail: jorge. elices.ocon@gmail.com
} 
Este artículo señala que al-Andalus constituye un escenario único para los estudios de recepción. Se pone de manifiesto la existencia de una profunda y novedosa reflexión sobre el pasado, que abarca varios aspectos. Por un lado, una llamativa reinterpretación de las estatuas clásicas, que pasan de ser consideradas ídolos paganos a ser vistas como imágenes talismánicas y protectoras de una ciudad o comunidad. Por otro lado, la apropiación y reelaboración del pasado por los cronistas árabes, con fines políticos y de legitimación.

\section{Palabras claves}

Al-Andalus; recepción; reutilización; estátuas, Califato de Córdoba; Legitimación.

Há oito anos, cheguei a Madrid para iniciar o mestrado de História e Ciência da Antiguidade, que hoje continua sendo oferecido com muito sucesso pelas universidades Complutense e Autônoma de Madrid. Uma das disciplinas ofertadas é a do Legado da Antiguidade, ministrada pela Profa. Gloria Mora Rodríguez (Universidade Autônoma de Madrid). O tema me chamou a atenção desde o primeiro momento, e devo confessar que até então eu sabia muito pouco a respeito desse legado e da sua recepção. Uma das minhas maiores surpresas foi a constatação de que os estudos a respeito desse tema não enfocam o que aconteceu no mundo islâmico. Ainda que as fronteiras clássicas não tenham coincidido com as do Império Romano, tampouco com as de Alexandre Magno, o mundo islâmico tem sido sempre excluído dessa perspectiva. O centro da atenção tem recaído sempre sobre a Europa cristã e a civilização ocidental, e o paradigma adotado é o de que as sociedades islâmicas sempre manifestaram uma recusa e um desinteresse por tudo que se relaciona à Antiguidade.

À medida que penetrei nesse tema, no entanto, descobri que tal perspectiva não corresponde à realidade e parece ser uma construção enviesada. Para mim, é cada vez mais evidente que os processos de recepção na Idade Média foram mais importantes e anteriores no mundo islâmico do que na Europa. Porém, em razão de condicionantes ideológicos ou religiosos, ou por barreiras linguísticas e acadêmicas, esses processos de recepção nunca foram considerados (Greenhalgh, 2009). Descobri então que a origem desse paradigma, que se repete sem questionar a sua veracidade, está nas ideias alegadas pelos viajantes e arqueólogos europeus dos séculos XVIII e XIX para justificar o saque e a pilhagem de antiguidades e seu traslado aos grandes museus e bibliotecas ocidentais. 'Na Europa, as antiguidades estariam seguras'. 'Na Europa, sim, elas seriam valorizadas e reconhecidas' (Gress, 1998; Tietze Larson, 1999/2000; Díaz-Andreu, 2007). Tal ideia foi expressa por Theodor Mommsen, quando se referiu ao islã como "o destruidor do helenismo"; a mesma ideia é ressaltada por imagens do tipo: 'os arqueólogos europeus' - a 
exemplo de Sir Austen Henry Layard em Nínive - 'descobrem, organizam e salvam antiguidades sepultadas sob a terra. Os habitantes locais seguem suas ordens de maneira disciplinada e obediente, cabendo-lhes apenas assombrarem-se, incrédulos, cada vez que uma estátua aparece'. 'Eles pensam que Layard quase possui poderes mágicos para ler inscrições e saber onde encontrar vestígios'. 'Os habitantes locais só concebem as ruínas para um uso imediato e destrutivo'. Um sarcófago servindo para lavar os pratos: essa é a imagem que nos transmitem. O outro lado da realidade nunca é mostrado. O discurso dos habitantes locais, seus vínculos com as ruínas e a história de saques e destruições protagonizadas e auspiciadas a partir do Ocidente compõem um aspecto que nunca é citado (Momigliano, 1950; Hamilakis, 2011; Schnapp, et al., 2013; Anderson e Rojas, 2017).

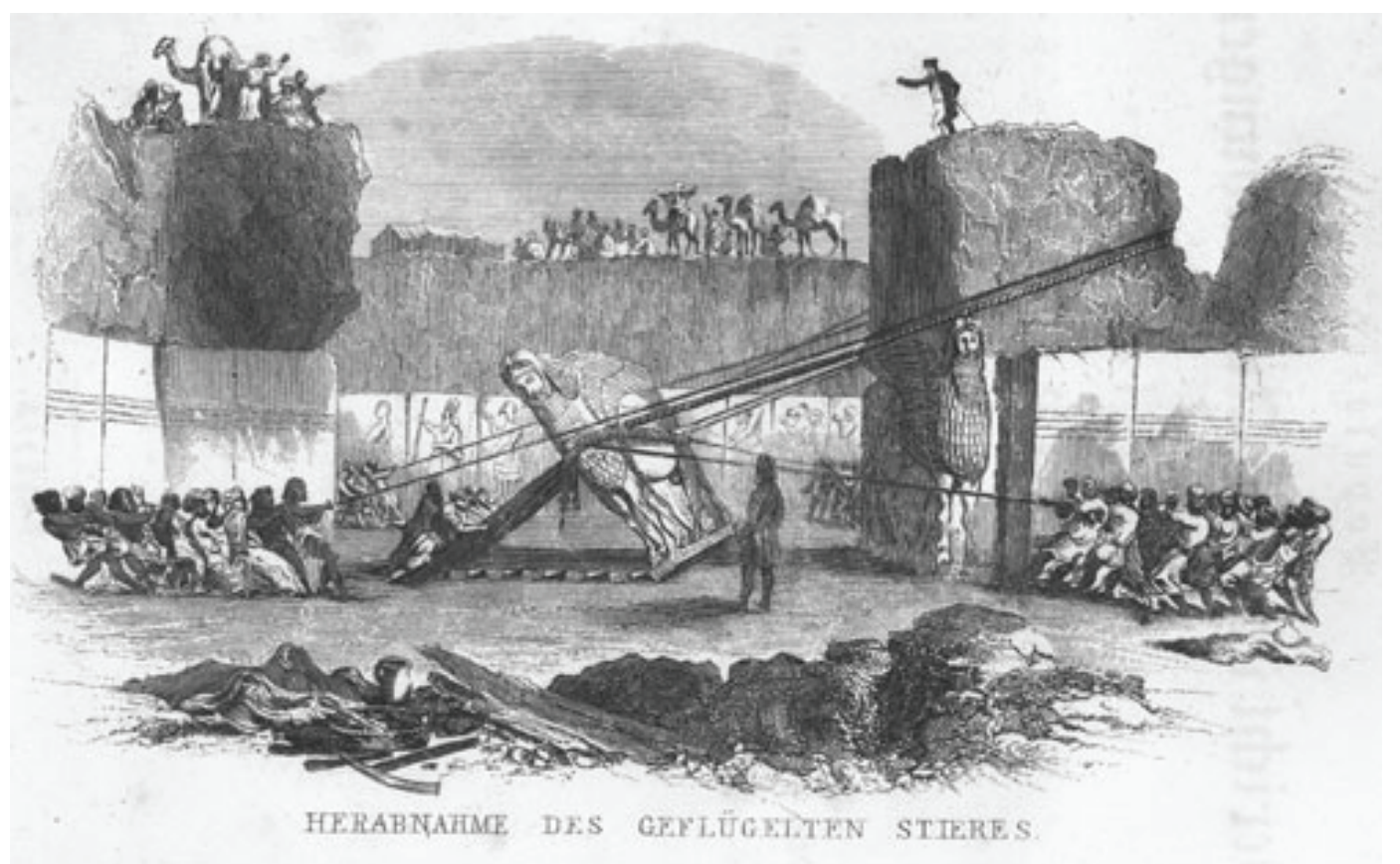

Figura 1: Gravura das escavações de Sir Austen Henry Layard em Nínive e Nimrud, com o achado dos famosos lamassus ou touros alados com cabeça de homem - hoje no Museu Britânico em Londres. Sir Austen Henry Layard, Nineveh and its remains, London, 1849, vol. 1, frontispício.

A partir disso, minha intenção foi descobrir até que ponto esse paradigma estava correto ou não. Eu desejava ver o que efetivamente dizem as fontes árabes e o registro material. Encontrei coisas realmente interessantes e comprovei que a realidade é muito mais complexa do que o que havia pensado. Descobri que no século IX, em Bagdá, aconteceu um processo muito importante de tradução de obras gregas. Isso era sabido no Ocidente. Por séculos, os autores se interessaram nesse processo. De fato, foi o único aspecto no qual 
aludiam ao mundo islâmico para dizer que, graças a ele, centenas de obras foram salvas e puderam ser posteriormente traduzidas ao latim. O seu trabalho salvaguardou um legado clássico que os europeus sempre consideraram como seu, mas que os autores árabes 'teriam sido incapazes de valorizar e aproveitar'. É a mesma ideia referida acima. Porém, encontrei nos textos árabes uma versão muito diferente da história, que afirmava que os muçulmanos eram os verdadeiros herdeiros e protetores do legado grego, e que os bizantinos, por sua vez, o teriam destruído e corrompido. Afirmou-se até mesmo que a ciência grega não era realmente grega, e sim, persa; e que foi Alexandre Magno que, ao conquistar o seu império, ordenou a tradução dessas obras e a queima das bibliotecas persas, para apropriar-se desse legado (Rosenthal, 1975; Sabra, 1987; Gutas, 1998).

A comprovação da existência de um discurso de apropriação tão semelhante em diferentes momentos e contextos me ajudou a entender a complexidade dos processos de recepção e a ver a necessidade do seu estudo. A professora Gloria Mora Rodríguez se mostrou entusiasmada em orientar-me, assim como o Dr. Eduardo Manzano Moreno (CSIC). Comecei assim a desenvolver minha tese doutoral, escolhendo a região de al-Andaluz e o período histórico omíada, que se me sobressaíram como um caso bastante interessante.

Esse interesse não era apenas fruto de uma proximidade. O período omíada é o momento imediatamente posterior ao ocaso do mundo antigo e ao início da formação de um Estado islâmico, quando a urbanização e a cultura da antiga Hispânia romana e visigoda continuavam presentes, convivendo com uma cultura latina então desconhecida do restante do mundo islâmico com a influência do grego, e onde também havia uma série de condicionantes, como a existência de uma fronteira frente ao mundo cristão, de uma dinastia diferente da que regia o restante do mundo muçulmano e de um momento de esplendor político e cultural no século X, no Califado de Córdoba (Acién Almansa, 1994 e 2000; Chalmeta, 1994; Manzano, 2006).

Porém, além de todas essas características próprias, havia três traços fundamentais que fazem de al-Andalus um cenário único para o nosso exame.

O primeiro desses aspectos é que, enquanto no Oriente se empregaram materiais reutilizados de modo muito pontual nos séculos VIII a X, em al-Andalus uma grande quantidade de peças foi buscada durante as épocas emiral e califal. Seus exemplos estão distribuídos ao longo de toda a Península Ibérica: os silhares e pilastras reutilizados na alcáçova e na cisterna de Mérida, as estelas encastoadas nas muralhas da fortaleza de Gormáz (Soria) e as peças visigodas dispostas sobre a ponte e o Portão de Alcântara em Toledo são alguns deles. 
Entretanto, há dois exemplares que são, sem dúvida, especialmente significativos (Finster, 2009; Peña 2010). A mesquita de Córdoba é o primeiro. Ela é o edifício que mais empregou materiais reutilizados no século VIII em todo o Mediterrâneo, inclusive mais do que as mesquitas construídas em Jerusalém e Damasco pelos próprios califas omíadas, e também mais do que as mesquitas de Samarra ou Bagdá, que foram erigidas pelos Abássidas. No primitivo oratório de Córdoba, construído em 170/786-7 por Abderramão I, contabiliza-se um total de 680 peças reutilizadas, incluindo fustes (geralmente lisos, mas também estriados, com contraestrias e helicoidais), capitéis (em sua maioria, coríntios ou pseudocoríntios, mas também jônicos, predominantemente da época júlio-claudiana), cimalhas e bases, das quais 360 teriam sido romanas. A essas peças, devem-se acrescentar outras 40 bases sob o atual pavimento, 90 cimalhas lisas e 190 peças tardo-antigas ou visigodas. Porém, as reformas realizadas por Abderramão III (que se resumiram ao minarete da mesquita) e as novas ampliações sob Aláqueme II e Almançor não empregaram peças reutilizadas, e sim colunas e capitéis talhados ex-novo. A única exceção está nas quatro colunas do mihrāb da ampliação de Aláqueme II, que foram trasladadas do que havia sido construído por Abderramão II, e em algumas colunas colocadas durante a ampliação de Almançor, que foram posteriormente removidas no século XVI (Ewert \& Wisshak, 1981; Cressier, 19841985; Peña, 2010).

Junto com a mesquita de Córdoba, outro exemplo extraordinário de reutilização de antiguidades está na cidade palatina de Medina Azhara, cuja construção foi ordenada por Abderramão III nos arredores de Córdoba, ao sopé da serra. Diferentemente da mesquita, este conjunto de peças foi reunido e utilizado na época califal, e não emiral. Além disso, ele não contém materiais construtivos mais ou menos apreciados, como colunas ou capitéis, e sim um destacado conjunto de sarcófagos lisos e figurados, além de diversas estátuas. Não se tem notícia de algo similar no restante do mundo islâmico durante o século X. O número atual de sarcófagos é 25, incluindo sarcófagos figurados, datados de entre meados e o segundo quartel do século III d.C.. Pelas suas dimensões e qualidade, ocupam um primeiro plano, e são peças excepcionais no contexto hispânico. Por sua vez, o conjunto de estátuas é menos numeroso, mas não menos importante: elas incluem um busto, cujo retrato ainda não temos, encontrado no pátio anexo à Dār alŷund; um herma que representa o Hércules-menino, ao qual falta a cabeça; e a cabeça de uma figura feminina datada do século III, procedente da esplanada em frente ao Pórtico. Com toda segurança, esse conjunto de antiguidades é um dos melhores casos no estudo da reutilização de peças em al-Andalus e no mundo islâmico, e é o melhor exemplo do zelo 'antiquarial' da dinastia omíada no século X (Beltrán Fortes, 1989-1990; Beltrán Fortes et al., 2006; Vallejo Triano 2010; Calvo Capilla, 2014). 


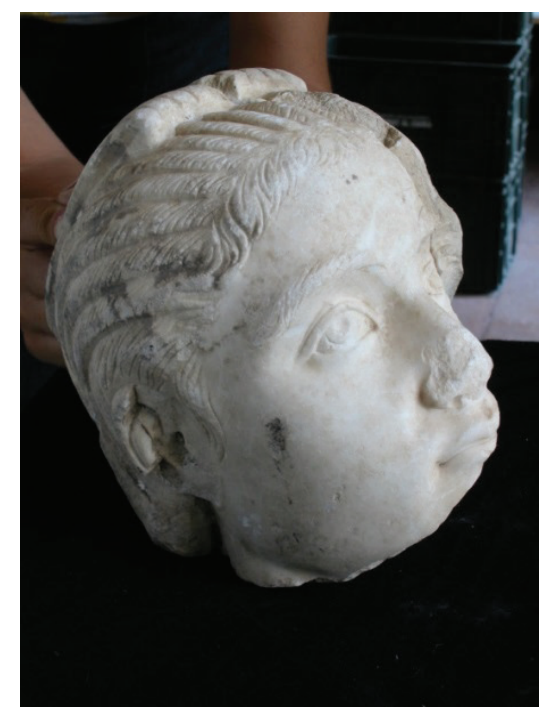

Figura 2: Cabeça feminina do século III d.C., procedente da esplanada em frente ao Pórtico em Madinnat al-Zahrā'. Imagem cedida pelo Conjunto Arqueológico Madinat al-Zahrā ${ }^{\prime}$ / Junta de Andaluzia.

O segundo dos aspectos que fazem de al-Andalus um lugar singular é o interesse precoce ou notório que o conhecimento da antiguidade parece ter-lhe suscitado. As notícias árabes ressaltam que o emir Abderramão II inquiria em todas as comarcas de al-Andalus em busca de colunas e instrumentos de todo tipo, reunindo-os e "levando-os à residência califal de Córdoba". Afirmam também que ele foi o primeiro a introduzir em al-Andalus os livros e ciências dos antigos, após ordenar que suas traduções fossem buscadas em Bagdá e trazidas a Córdoba (Ibn Hayyān, Muqtabis II-I, trad. de Makkī e Corriente, 2001, f. 139v e 143v). O apreço e interesse pela antiguidade abarcam todos os seus aspectos. Por exemplo, Aláqueme II, reconhecido por sua inclinação à sabedoria e seus gostos bibliófilos, ordenou a busca de obras e traduções dos sábios greco-latinos, reunindo uma biblioteca com um acervo estimado de 400.000 exemplares - sem dúvida, um número exagerado, mas que, mesmo assim, foi certamente notável. As suas estantes continham diversas obras que os relatos de autores árabes mencionam ter chegado a al-Andalus. Por exemplo, havia um original grego do De Materia Medica de Dioscórides, e o Livro das Causas de (Pseudo) Apolônio de Tiana, ambos enviados pelo imperador bizantino de Constantinopla como presentes para o príncipe. Fruto também de contatos diplomáticos neste caso, com o conde catalão Suñer -, chegou às mãos do príncipe Aláqueme o Livro dos reis francos, outra obra histórica a respeito dos reis merovíngios e carolíngios (Wasserstein, 1990-1991-1993; Signes, 1996, 184; Barceló i Roca, 1979).

As notícias relativas às ruínas de al-Andalus também estão cheias de referências extraordinárias. Uma das mais relevantes alude à descoberta de uma 
fabulosa inscrição em Mérida. A notícia está ligada, em última instância, a Aḥmad al-Rāzī e aparece como parte de um diálogo a respeito do mármore e das antiguidades que existiam em Mérida, diálogo este protagonizado por 'Umar, um dos filhos do emir Aláqueme I, e al-'Āṣi b. 'Abd Allāh b. Ta'laba, general de Abderramão II e governador e construtor da alcáçova de Mérida. Precisamente este último ressalta:

Tornei-me atento à qualidade dos seus mármores (ruhām). Quando fui governador de Mérida, sempre que encontrava algum tipo de mármore que me agradava, pedia que o trouxessem a mim. Um dia, passeando pela cidade, notei uma lápide de mármore esculpida na muralha (lūj fī sūrha), no momento em que caía sobre ela abundantemente água. Parecia, à primeira vista, estar vendo uma autêntica joia [...] ordenei que a tirassem da muralha e, ao extraí-la, descobriu-se uma gravação em língua cristã (kutub al-'aŷam). Reuni os cristãos que se encontravam em Mérida para traduzi-la [...] e um deles me assegurou que apenas um cristão poderia fazê-lo, porque foi composta em sua língua. Enviei um mensageiro expressamente para trazê-lo e me encontrei com um clérigo velho e decrépito. Segurando a lápide (lūj) entre as mãos, seus olhos se encheram de lágrimas, enquanto ele me dizia: "O que está inscrito nesta gravação é um documento do povo de Îliyā, que construiu a muralha e deu-lhe uma altura de 15 côvados".

Al-Rušățĭ, Iqtibās, p. 54-5, com texto árabe e tradução em Torres Calzada (2014): 255-6 e 243-4.

São muitos os aspectos evidenciados por essa notícia: a consideração especial que as inscrições suscitavam, o apreço pelo mármore, a evidência do espólio de materiais, a sobrevivência do latim e a suposta habilidade de um ancião ao decifrar a inscrição. A esse respeito, é importante destacar que a notícia está marcada por diferentes tópoi (por exemplo, o descobrimento de um objeto maravilhoso ou a figura de um sábio ou ancião que decifra um conhecimento ancestral e revelador). Entretanto, a notícia está incluída no contexto verossímil do ambicioso projeto de transformação da cidade, que ensejou a construção da alcáçova e o desmantelamento parcial da muralha de Mérida por ordem de Abderramão II como castigo pela rebeldia da cidade. De fato, pode se tratar de uma verdadeira epígrafe, talvez a mesma que se documentou ter sido reutilizada na alcáçova de Mérida como imposta do arco de sua entrada, e que foi recortada a fim de se encaixar nesse lugar. Ela alude à dedicação de uma igreja à Santa Maria sob a defesa de Sancta Ierusalem, Îliyā, ou Jerusalém segundo os árabes (Navascués e de Juan, 1948: 309-310 e 354).

Por fim, o terceiro aspecto que faz de al-Andalus um cenário único são as fontes árabes andaluzes. Tradicionalmente, as fontes árabes relativas ao passado não foram consideradas como algo mais do que elementos fantásticos, cuja 
informação e utilidade histórica e científica eram, no mínimo, questionáveis. Porém, as fontes árabes mostram um conhecimento detalhado das fontes clássicas, incluem episódios e detalhes históricos de grande fiabilidade e até mesmo agregam novas informações à luz das descobertas arqueológicas que então aconteciam e eram capazes de complementar os seus relatos.

Duas obras merecem especial atenção: a tradução árabe das Histórias de Orósio - o Kitab Hurusiyus - e o relato acerca do passado pré-islâmico escrito pelo historiador cordobês Aḥmad al-Rāzī (m. 344/955). Ambas as obras percorrem fontes clássicas para narrar diversos acontecimentos da história universal e peninsular, mencionando figuras como Hércules, Viriato, Júlio César, Augusto, Constantino ou Leovigildo. Não existe nada parecido com isto no restante do mundo islâmico medieval. Em especial, a obra de Aḥmad al-Rāzī, por sua concepção da Península como sujeito histórico, é algo realmente notório e só se compara ao projeto historiográfico de Alfonso X, realizado três séculos depois (De Gayangos, 1850: 5-10; Levi della Vida, 1954; Crónica de Moro Rasis, 1975; Sánchez-Albornoz, 1967: 267-375 e 1978; Molina, 1982-3 e 1984; Penelas, 2001).

Assim, minha tese se concentrou no estudo das fontes árabes e registros materiais que evidenciassem quais eram os padrões e os processos de recepção da antiguidade em al-Andalus durante o período omíada (92/711-422/1031). Analisei as fontes árabes relativas ao passado pré-islâmico peninsular, aos monumentos antigos que ainda eram visíveis e às referências que os autores dedicaram às ciências e às obras dos autores greco-latinos, e indiquei o que foi destruído do passado em al-Andalus, e por que, e o que interessou ser conservado, e por que. A esse respeito, duas conclusões são, a meu ver, especialmente significativas.

\section{A reinterpretação das estátuas clássicas: de ídolos pagãos a talismãs}

As notícias relativas a estátuas são um dos aspectos mais interessantes das fontes árabes e das evidências testemunhadas pela arqueologia. Sua reutilização obedece a critérios práticos e estéticos, como em outros casos. Por exemplo, a localização dessas imagens figuradas em um lugar em particular - junto às portas e muralhas das cidades andaluzas - pode ter tido uma razão meramente prática: muitos dos cemitérios se encontravam nos arredores das cidades e seria fácil deixá-las próximo às portas como material transportado (Greenhalgh, 2009: 221). Entretanto, outros critérios também devem ser considerados. Por um lado, as portas e muralhas das cidades são um símbolo dessas mesmas cidades, uma demonstração do seu poderio militar e riqueza. Por outro, as fontes árabes indicam que essas estátuas e imagens eram consideradas 
talismãs e tinham propriedades mágicas ligadas à astrologia, utilizando em casos concretos a palavra 'talismã' (tilasm).

Tudo isso nos revela um aspecto extremamente interessante, pois essa singular reinterpretação das estátuas pré-islâmicas serve precisamente para vencer as resistências que poderiam inspirar visões ligadas sempre à ŷāhiliyya e ao paganismo, e integrá-las ao presente andaluz, reinterpretando-as e identificando nelas uma função. De fato, pode-se argumentar que as destruições e mutilações de imagens que citávamos antes têm, na verdade, a intenção de 'neutralizar' essas estátuas e retirar justamente o seu componente mágico (Flood, 2002, 648 e 2006).

A reinterpretação mágica dessas estátuas é um fenômeno bem conhecido e bem documentado na tardo-antiguidade e em outras regiões do Mediterrâneo. Na verdade, a conexão com o antigo paganismo é talvez o aspecto mais atraente dessa reinterpretação islâmica das estátuas clássicas. A origem dessa conexão parece estar ligada justamente às comunidades helenizadas dos sabeus de Harã, onde a ligação com as tradições herméticas e astrológicas parecem estar na base dessas ideias (Pingree, 2002). De fato, a conexão entre os talismãs e a astrologia aparece de vez em quando nas fontes andaluzas, de tal maneira que é possível apontar uma possível relação entre essas notícias e o desenvolvimento das ciências dos astros em al-Andalus já na segunda metade do século $X$, quando surgiram obras que se aprofundaram nessa conexão entre a astrologia e a magia talismânica.

As estátuas e imagens talismânicas eram definidas por aspectos ou características que estão evidenciados nas notícias: uma localização específica e precisa, mencionando com frequência uma origem pré-islâmica; e sua eficácia se sustenta por analogia, isto é, pela imagem do objeto sobre o qual um talismã exerce o seu poder. Tais estátuas e imagens estão gravadas em pedra, mármore, bronze, ouro ou outro metal precioso, e seu poder se baseia em uma correspondência com, ou influência de entes superiores que, em geral, estão ligados a um planeta ou figura celeste. Graças a isso, elas são capazes de proteger uma cidade, região ou até mesmo um país frente a qualquer tipo de ameaça (ataques por inimigos, invasões ou pragas e doenças). Mas se o talismã for alterado de alguma maneira, dissolve-se o seu encantamento e ele deixa de ser eficaz (Flood, 2006).

\section{O relato da história pré-islâmica: um discurso de legitimação}

A segunda conclusão a se destacar está ligada precisamente à singularidade apresentada pelo relato da história pré-islâmica pelos autores árabes no século X. Naquele momento, havia um interesse em conhecer e elaborar um 
relato dos reis e povos que dominaram a Península Ibérica antes da chegada dos muçulmanos.

Essa narração, atribuível a Aḥmad al-Rāzī, está construída a partir das fontes clássicas e as segue, em muitas ocasiões, de forma fidedigna e detalhada. Contudo, pode-se identificar também uma contínua reelaboração desses relatos. Por exemplo, o próprio Aḥmad al-Rāzī complementa o relato do Kitāb Hurūšiyūs com outras fontes, como a crônica de São Jerônimo ou a de Juan de Bíclaro, enquanto, na segunda metade do século $X$, outros autores também estavam obtendo o relato do historiador cordobês.

Em qualquer caso, os autores andaluzes não se limitaram simplesmente a copiar ou traduzir essas notícias, com seus acertos e seus erros, mas também elaboraram uma narrativa nova e original, incorporando tradições orientais, por exemplo, as que aludem à origem oriental dos išbān, um povo que teria conquistado a Península, fundando muitas cidades e dando o seu nome, Hispânia ou Išbāniya - para complementar a versão clássica a partir dos autores latinos, que menciona Išbān como um mítico rei antigo (San Isidoro, Etimologias, XIV, IV, 28 e Ibn Ḥabīb, K. Ta'rìj, 138, no 397).

Os autores árabes também incluíram tradições locais ou autóctones, por exemplo, a tradição relativa à origem da Era Hispânica (38 a. C), um antigo sistema de datação empregado na Península, conhecido pelos autores árabes como a Era de Bronze (Ta'rīj aṣ-șufr) uma vez que sua origem estaria na pavimentação com placas de bronze do leito do Rio Tibre em Roma, graças à arrecadação de um imposto pago nesse metal no quarto ano do reinado de Otávio Augusto (San Isidoro, Etimologías, V, 36, 4; K. Hurūšìūs, 335 no 9; Levi della Vida, 1943).

Por fim, os autores árabes também mencionaram todo tipo de referência provinda das descobertas arqueológicas que aconteceram em sua época, bem como do estudo de ruínas antigas. Por exemplo, citaram diversos objetos encontrados durante a conquista islâmica em cidades como Toledo e Mérida, aos quais atribuíram uma origem pré-islâmica e oriental, como a Mesa de Salomão, e que parecem corresponder aos despojos saqueados pelos conquistadores nas igrejas hispanas. Também incluíram referências a estátuas escavadas da terra, por exemplo, em Itálica, e à descoberta de inscrições, como a de Mérida, ou como a inscrição localizada em uma igreja próxima a Guadix, na qual o aparecimento do nome de Recaredo serviu para que os autores árabes relacionassem a sua construção ao rei Visigodo e mencionassem esse dado ao relatarem a respeito do seu reinado (Ibn Habīb, Ta'rīj, 140; Al-Bakrī, K. al-masālik, 1517 e 1522; Hernández Juberías, 1996: 194-208).

À luz dessas características, surge a impressão de que os autores árabes buscaram criar um relato tão completo, verossímil e aceitável quanto possível. 
Isso evidencia que em al-Andalus no século $X$, existiu um interesse pela antiguidade que ia mais além da mera curiosidade ou do entretimento, buscando oferecer um relato único a respeito dos feitos do passado, que reelaborava a memória coletiva da Hispânia e assentava as bases de uma nova identidade local. Porém, além disso, o relato histórico traçado por esses autores - em especial, o que se atribui a Ahmad al-Razi - é um discurso de legitimação.

Em termos concretos, esse discurso histórico é uma narração alternativa à das crônicas asturianas, que foram redigidas no reino das Astúrias no final do século IX sob os auspícios de Alfonso III. O objetivo das crônicas asturianas era o de consolidar a ideologia da reconquista, asseverando que os monarcas asturianos descendiam dos reis visigodos e tinham, assim, legitimidade para governar sobre toda a Península. O relato de Ahmad al-Razi é a resposta a esse discurso. Porém, enquanto as crônicas asturianas apenas incluem uma breve descrição dos imperadores romanos e reis visigodos, a obra do cronista cordobês é muito mais ambiciosa, mencionando diversos outros detalhes e incluindo episódios e personagens, a exemplo das referências a Hércules ou à história pré-romana. Essas citações não aparecem nas crônicas asturianas e diferem, em alguns pontos, do relato que elas oferecem, em particular, no tocante ao papel desempenhado pelos últimos reis visigodos, Witiza e Rodrigo. Tudo isso visava não apenas a oferecer uma explicação satisfatória a respeito da origem das cidades e ruínas de al-Andalus, mas também a contribuir para lavrar uma nova legitimidade para o recém-fundado Califado de Córdoba (Gil Fernández, Moralejo e Ruiz de la Peña, 1986).

\section{Conclusões}

A obra de Aḥmad al-Rāzī constitui um marco da historiografia árabe-islâmica medieval e hispano-medieval. A ambiciosa perspectiva global apresentada pelo seu relato, que trata a Península Ibérica como uma protagonista e traça uma narrativa completa da sua história pré-islâmica, é uma referência enormemente singular e poderosa. $\mathrm{O}$ sentido do seu surgimento deve ser buscado no contexto político andaluz da primeira metade do século X, do mesmo modo como no caso do Kitāb Hurūšiyūs, e também na necessidade de engendrar uma legitimação política capaz de dar resposta aos novos problemas e desafios ligados à instauração do Califado de Córdoba, traçando uma comparação entre o passado e o presente. O seu propósito era não outro que o de resgatar do passado uma visão capaz de explicar e justificar o presente e a realidade visível dos seus momentos. Possuía, assim, um objetivo claramente pragmático, mas também político ou ideológico, que deve ser traçado em relação ao círculo omíada do qual o historiador cordobês foi um estreito colaborador. Sem dúvida, o passado 
foi construído em al-Andalus de forma paralela à progressiva arabização e implantação de um Estado islâmico centralizado, e foi uma ferramenta fundamental - da qual se usou e abusou - para reelaborar antigas memórias e lealdades, e transformá-las em uma única visão dos fatos, capaz de englobar discursos alternativos e identidades distintas.

\section{Fontes}

Al-Bakrī. Kitāb al-Masālik wa-l-mamāik. Edição, Van Leeuwen, A. P./Ferré, A. 2 vols. Túnez: Servicio de Publicaciones, 1992.

Crónica del Moro Rasis. Edição, Catalán, D./ De Andrés, Mª S. Madrid: 1975.

Crónicas asturianas. Edição, Gil, J./Moralejo, J. L./Ruiz de la Peña, J. I. Oviedo: Servicio de Publicaciones, 1986.

Ibn Ḥabīb. Kitāb al-ta'rīj. Edição, Aguadé, J. Madrid: Publicaciones CSIC, 1991.

Ibn Ḥayyān. Muqtabis II-I. Crónica de los emires Alhakam I y Abdarrahman II entre los años 796 y 847. Tradução, Makkī, M. A./Corriente, F. Zaragoza: 2001.

Isidoro de Sevilha. Etimologías (Etymologiae). Edição e tradução, Oroz Reta J. e Marcos Casquero. 2 vols. Madrid: Biblioteca de Autores Cristianos, 1982.

Kitāb Hurūšìūs. Kitāb Hurūšiyūs: traducción árabe de las "Historiae adversus paganos" de Orosio. Edição Penelas, M. Madrid: Publicaciones CSIC, 2001.

Al-Rušăți. Andalus en el Kitāb iqtibās al-anwār y en el Ijtișār iqtibās al-anwārr. Edição Molina López, E./Bosch-Vilá, J. Madrid, 1990.

\section{Referências Bibliográficas}

ACIÉN ALMANSA, M. Entre el feudalismo y el islam. Úmar ibn Hafșun en los investigadores, en las fuentes y en la historia. Jaén: Servicio de Publicaciones, 1994.

- La herencia del protofeudalismo visigodo frente a la imposición del estado islámico. In: CABALLERO, L. e MATEOS, P. (eds.). Visigodos y omeyas: un debate entre la Antigüedad tardía y la Alta Edad Media. Madrid: Publicaciones CSIC, 2000.

ANDERSON, B. e ROJAS, F. (eds.). Antiquarianisms: contact, conflict, comparison. Oxford: Oxbow Books, 2017. 
BARCELÓ, M. Una nota entorn del «Llibre dels reis francs» regalat pel bisbe Gotmar de Girona, l'any 380-940, a Al-halkam, a Còrdova. Annals de l'Institut d'Estudis Gironins. Girona: 25, 1, 1979, pp. 127-136.

BELTRÁN, J. La colección arqueológica de época romana aparecida en Madinat al-Zahra. Cuadernos de Madinat al-Zahra. Córdoba: 2, 1988-90, pp. 109-126.

BELTRÁN FORTES, J. et al. Los sarcófagos romanos de Andalucia. Murcia: Servicio de Publicaciones, 2006.

CALVO, S. The reuse of classical antiquity in the palace of Madinat al-Zahra and its role in the construction of caliphal legitimacy. Muqarnas. Nova York: 31, 1, 2014, pp. 1-33.

CHALMETA, P. Invasión e islamización. La sumisión de Hispania y la formación de al-Andalus. Madrid: Maphre, 1994.

CRESSIER, P. Les chapiteaux de la grande Mosquée de Cordoue (oratoires d' 'Abd al-Rahman I et d' 'Abdar-Rahman II) et la scuplture de chapiteaux à l'époque émirale. Première partie. Madrider Mitteilungen. Frankfurt: 25, 1984, pp. 216-281 e 26, 1985, pp. 257-313.

DE GAYANGOS, P. Memoria sobre la autenticidad de la Crónica denominada del moro Rasis. Memorias de la Real Academia de la Historia. Madrid: 8, 1850, pp. 21-100.

DÍAZ-ANDREU, M. A world history of nineteenth-century archaeology: nationalism, colonialism, and the past. Oxford: Oxford University Press, 2007.

EWERT, C. e WISSHAK, J.-P. Forschungen zur almohadischen Moschee I. Vorstufen: Hierachische Gliederungen westislamischer Betsäle des 8. bis 11. Jahrhunderts: Die Hauptmoscheen von Qairawan und Córdoba und ihr Bannkreis, Mainz: 1981.

FINSTER, B. Die Werwendung von Spolien in umayyadischer Zeit. In: SCHATTNER, T. G. e Valdés, F. (Eds.). Spolien im Umkreis der Macht / Spolia en el entorno del poder. Actas del coloquio en Toledo del 21 al 22 de Septiembre de 2006. Mainz, 2009.

FLOOD, F. B. Between cult and culture: Bamiyan, Islamic iconoclasm, and the Museum. The Art Bulletin. Nova York: 84, 4, 2002, pp. 641-659.

- Image against nature: Spolia as apotropaia in Byzantium and the dar al Islam. The Medieval History Journal. Londres: 9, 1, 2006, pp. 143-166.

GREENHALGH, M. Marble past, monumental present. Building with antiquities in the mediaeval Mediterranean. Leiden/Boston: Brill, 2009. 
GRESS, D. From Plato to NATO: The idea of the West and its opponents. New York: Free Press, 1998.

HAMILAKIS, Y. Indigenous archaeologies in Ottoman Greece. In: BAHRANI, Z., ÇELIK, Z., e ELDEM, E. (eds.). Scramble for the past: a story of archaeology in the Ottoman Empire, 1753-1914. Istambul: Salt, 2011.

HERNÁNDEZ, J. La península imaginaria: mitos y leyendas sobre al-Andalus. Madrid: Publicaciones CSIC, 1996.

LEVI DELLA VIDA, G. The Bronze Era in Moslem Spain", Journal of the American Oriental Society. Pensilvânia: 63, 3, 1943, pp. 183-191.

- La traduzione araba delle Storie di Orosio. Al-Andalus. Madrid: 19, 1954, pp. 257-293.

MANZANO, E. Conquistadores, emires y califas. Los omeyas y la formación de al-Andalus. Barcelona: Crítica, 2006.

MOLINA, L. Sobre la procedencia de la Historia preislámica inserta en la Crónica del moro Rasis. Awraq. Madrid: 5-6, 1982-3, pp. 133-139.

- Orosio y los geógrafos hispanomusulmanes. Al-Qantara. Madrid: 5, 1984, pp. 63-92.

MOMIGLIANO, A. Ancient history and the antiquarian. Journal of the Warburg and Courtauld Institutes. Londres: 13, 3-4, 1950, pp. 285-315.

NAVASCUÉS, J. Ma . La dedicación a la iglesia de Santa María y de todas las vírgenes de Mérida. Archivo Español de Arqueología. Madrid: 21, 73, 1948, pp. 309-350.

PEÑA, A. Estudio de la decoración arquitectónica romana y análisis del reaprovechamiento de material en la Mezquita Aljama de Córdoba: Córdoba: Servicios de Publicaciones, 2010.

PINGREE, D. The Sabians of Harran and the classical tradition. International Journal of the Classical Tradition. Londres: 9, 2002, pp. 8-35.

ROSENTHAL, F. The classical heritage in Islam. London: Routledge \& Kegan Paul, 1975.

SÁNCHEZ-ALBORNOZ, C. Investigaciones sobre historiografía hispana medieval. Buenos Aires: Editora Nacional, 1967

- Adiciones al estudio de la Crónica del moro Rasis. Madrid: Cátedra, 1978. 
SCHNAPP, A. et al. World antiquarianism: comparative perspectives. Los Angeles: Getty Research Institute, 2013.

SIGNES CODOÑER, J. La diplomacia del libro en Bizancio. Algunas reflexiones en torno a la posible entrega de libros griegos a los árabes en los siglos VIII-X, Scrittura e Civiltà. Roma: 20, 1996, pp. 153-187.

TIETZE LARSON, V. Classics and the acquisition and validation of power in Britain's 'Imperial Century' (1815-1914). International Journal of the Classical Tradition. Londres: 6, 1999/2000, pp. 185-225.

TORRES CALZADA, K. El emeritense: noticia de la ciudad de mérida recogida en el Iqtibās al-anwā̄ de Abū Muhammad al-Rušățī (466/1074-542/1147). Miscelánea de Estudios Árabes y Hebraicos. Sección Árabe-Islam. Granada: 63, 2014, pp. 233-256.

VALLEJO, A. La ciudad califal de Madinat al-Zahra. Arqueología de su arquitectura. Córdoba, Almufara, 2010.

VALLVÉ, J. Fuentes latinas de los geógrafos árabes. Al-Andalus, 32, 1967, pp. 241-260.

WASSERSTEIN, D. J. The library of al-Hakam II al-Mustansir and the culture of Islamic Spain, Manuscripts of the Middle East. Londres: 5, 1990-1991-1993, pp. 99-105. 